This PDF is a selection from an out-of-print volume from the National Bureau of Economic Research

Volume Title: Tax Policy and the Economy, Volume 6

Volume Author/Editor: James M. Poterba, editor

Volume Publisher: The MIT Press

Volume ISBN: 0-262-66077-6

Volume URL: http://www.nber.org/books/brad92-1

Conference Date: November 19, 1991

Publication Date: January 1992

Chapter Title: Taxation and Inequality: A Time-Exposure Perspective

Chapter Author: Joel B. Slemrod

Chapter URL: http://www.nber.org/chapters/c10841

Chapter pages in book: (p. $105-128)$ 


\section{TAXATION AND INEQUALITY: A TIME-EXPOSURE PERSPECTIVE}

\section{Joel Slemrod}

The University of Michigan and NBER

\section{INTRODUCTION}

There is a wide consensus among economists that the distribution of income in the United States recently has become more unequal. Most observers believe that this trend was well under way by 1980; many trace its origin to as early as 1970 . There is less consensus about the causes of the growth in inequality. Among the competing hypotheses are a shift in demand toward high-skilled labor and away from unskilled labor, an increase in the relative supply of low-skilled workers, and a shift in output toward sectors where individuals' productivities are more variable and more easily identified.

There is virtually no consensus about the role of the tax system in the growth in inequality, and swirling controversy about the appropriate tax policy response to this trend. For example, Gramlich, Kasten, and

Prepared for the National Bureau of Economic Research Conference on Tax Policy and the Economy, to be held November 19 in Washington, D.C. I am grateful to Marianne Page and Alec Rodney for exemplary research assistance, and to Shlomo Yitzhaki for providing key computer programs used in the analysis. Helpful comments on an earlier draft were provided by Don Fullerton, Roger Gordon, Ned Gramlich, Rick Kasten, Donald Kiefer, Jim Poterba, Frank Sammartino, Bob Williams, and Shlomo Yitzhaki. 
Sammartino (1991) have claimed that, in the 1980s, the tax system became slightly less effective in reducing the inequality in pre-tax incomes. Lindsey (1990) has argued that the precipitous drop at the start of the 1980s in the marginal tax rate imposed on higher income individuals was a principal cause of the increased apparent inequality of pre-tax incomes, because it has encouraged these individuals to work more, report more income, realize more capital gains, and convert nontaxed compensation to taxable compensation. Finally, many of the tax policy changes currently being advocated, in particular the child credit financed by higher tax rates on higher-income taxpayers, are justified in part as an attempt to offset the increase in income inequality.

Nearly all of the conclusions about the trend in inequality and the role of the tax system have been based on cross-sectional snapshots of annual income. Yet it is well known that conclusions based on snapshots can give a misleading picture of the inequality of a more permanent notion of income, due to the mobility of individuals across annual income classes. Specifically, transitory income will give the appearance of greater inequality in a one-year snapshot than over a longer period. If the relative importance of transitory income has changed over time, then the trends in the inequality of annual income may misstate the trends in a more permanent notion of income. Furthermore, most of the conclusions about inequality have been based on either labor earnings or the Current Population Survey (CPS) definition of money income, which excludes capital gains, poorly measures other capital income, and is subject to coded maximum values.

In this paper I make use of tax return data that has extensive information on property income, and in particular two longitudinal tax return data bases that follow an unchanging sample of taxpayers from 1979 to 1986, and a distinct set of taxpayers from 1967 to 1973, in order to reassess some of the conclusions about taxation and inequality. The paper is arranged as follows. Section II provides a brief review of what is known, based on snapshots, of inequality over the past two decades. Section III utilizes tax return data to investigate some of these same issues, with an emphasis on decomposing the trends by source of income. In Section IV I bring to bear the 1979-1986 longitudinal data file of tax returns, and reassess some of the earlier results; Section V compares these results to the 1967-1973 panel. Section VI summarizes the findings and restates the caveats to be applied to these findings. 


\section{INEQUALITY AND TAXES:}

\section{A BRIEF REVIEW OF THE LITERATURE}

\section{A. Trends in Inequality}

There is a broad consensus that income inequality has been increasing in the last two decades. There is evidence of increased dispersion since the mid-1970s in both the lower and upper tails of the distribution for families and for individuals, and in the distribution of labor income for workers. At least since 1979, inequality has grown both between less and more educated workers and also among apparently similar workers. As Karoly (1991) has documented, this conclusion is robust to a great variety of disaggregations, including by families with children and raceethnicity. The increase in inequality among workers cannot simply be explained by shifts in the gender, education or experience composition of the work force, and is evident even when the sample is restricted to full-time workers.

Several alternative explanations have been offered to the increased inequality. Most attention has been paid to labor market factors, as labor market income accounts for about 70 percent of family income. Among the supply explanations offered are shifts in the size of worker-age cohorts and the educational distribution of these cohorts. Among the demand explanations offered are shifts in the composition of final output, in the occupational mix within industries, in skill requirements, and in the density of unionization. The strength of the evidence supporting these not mutually exclusive explanations is assessed in Levy and Murnane (1991).

\section{B. Taxes as an Offset to Growing Inequality}

Although the CPS measure of income is before taxation, it is clear that after-tax income is a superior measure of well-being. With that in mind, it is interesting to know to what extent the tax system has offset, or exacerbated, the increased inequality in pre-tax income. Using CPS data supplemented by data from tax returns, Gramlich, Kasten, and Sammartino (1991) conclude that during the 1980s tax and transfer policy changes became less effective in reducing pre-tax income inequality. As a result, after-tax income inequality increased by even more than pre-tax income inequality. Of a 16.5 percent increase in the Gini coefficient of post-tax, post-transfer income between 1980 and 1990, they attribute 40 percent to the decline in the redistributive effectiveness of the federal tax and transfer system, with the 40 percent about equally divided between taxes and transfers. Some of the change in the distribution of transfers and taxes 
was, however, the result of economic and demographic changes rather than explicit changes in policy. When they hold the distribution of pretax, pre-transfer income at its 1990 level but adjust transfers and taxes to reflect 1980 law, only 16 percent of the increase in the inequality of posttax, post-transfer income was due to policy changes. Most of these policy changes involved a decrease in the progressivity of federal taxes, due to the increased importance of the regressive social security taxes; also significant was a fall in the share of transfers going to low-income people.

\section{Taxes as an Inducement to Growing Inequality}

The previous calculation ignores the possibility that the tax system induces changes in pre-tax income. Lindsey (1990) has argued that in the early 1980s the sharply reduced marginal tax rates at the top (which fell in 1981 from 70 percent to 50 percent, in 1987 to 39 percent, and in 1988 to 28 percent) induced high-income taxpayers to work more hours, report a higher share of their income to the Internal Revenue Service, realize more capital gains, take more compensation in taxable form, and generally substitute taxable income for either nontaxed income or leisure.

This argument implies that much of the apparent increase in the dispersion of income in the 1980s is illusory. The high incomes were there, prior to 1981, but they were in forms that would either not appear in the standard data sets on income, not be realized income sources, or were potential income consumed in the form of leisure. This important and controversial claim is not addressed directly in the analysis that follows, although the data sources described next can help to assess its validity.

\section{Public Finance Implications of Inequality}

An accurate picture of the distribution of income and its sources is critical for at least two important questions in public finance: How is the burden of any given tax system shared by individuals, and how should the tax burden be shared across income classes?

There are two steps to understanding how the burden of taxation is borne. In the first step, known to economists as the question of tax incidence, knowledge of the price sensitivity of supply and demand is used to predict the extent to which a tax will be borne by the statutory bearer of the burden-the "check writer" - and the extent to which the burden will be shifted to others through changes in prices. In the second step the conclusions about how prices will be affected is translated into how families' well being is changed. This step requires information about the distribution of wealth, potential labor income, and tastes. For example, once a judgment is made about how a cigarette tax will change the price of cigarettes and the value of tobacco land, one needs to know 
the distribution of demand for cigarettes, unskilled labor, and ownership of tobacco land.

The distribution of income-earning ability is also a critical input into the modern theory of optimal tax progressivity, which poses the problem as a tradeoff between the social benefit of a more equal distribution of well-being and the disincentive cost of the tax and transfer system needed to effect a more equal distribution. In the standard models of this literature, described in Slemrod (1983), a more unequal distribution of inherent abilities - or the return to these abilities-increases the optimal degree of progressivity because it increases the social value of the redistribution accomplished for any given degree of tax progressivity. Another strand of the literature, exemplified by Varian (1980), stresses the social insurance function of progressive taxation. In this framework, an increase in exogenous variability of income would also increase the optimal degree of progressivity, because it increases the insurance value of the progressivity.

\section{SNAPSHOT DISTRIBUTIONS}

\section{A. Why Snapshots May Mislead}

Many of the conclusions about the distribution of these factors are based on snapshots of the distribution taken at a point of time. It is critical to realize, however, that snapshots of distributions can give a highly misleading picture of the distribution of a more permanent notion of income or well-being. As an illustration, consider an economy of individuals who are identical except for their age, where each individual follows the same life-cycle pattern of increasing labor income over the working years, followed by a period of retirement with no labor income. A snapshot of the distribution of labor income would conclude that to the extent a tax lowers after-tax wage income, it will have a highly skewed burden distribution, severely affecting some individuals (the working young) and leaving others unscathed (the retired elderly). But, of course, from a lifetime perspective (except for transitional effects) everyone is equally affected, as everyone will at some time be at the high labor income age and also the retirement age. In addition to life-cycle effects, a measure of inequality based on a snapshot will capture intercohort effects due to real income growth over time.

This paper focuses on a separate reason why a snapshot may give a misleading picture of the distribution of income sources-transitory income. An example will best convey the problem. Imagine an economy where individuals have but two sources of income. One source, which I 
will call labor income, is equally distributed across individuals and stable over time. The other source, which I will call capital gains, also is equally distributed but is also highly unstable over time; every so often an exogenous process conveys capital gains income to some individuals. A snapshot of any year's distribution of income sources will reveal two "facts": (1) that the distribution of total income is more unequal than that of labor income alone and (2) that capital gains are a more important source of income for high-income individuals. These facts will appear even though, over the long run, capital gains income is distributed no differently than labor income and all individuals have equal income.

There is one more twist to this story. In the above illustration it was assumed that the time pattern of capital gains income was exogenously determined. In reality the timing of the realization of income for tax purposes may be subject to a great deal of control by the individual. In particular, because of the graduated nature of the income tax system, there is an incentive for individuals to use their discretion over the timing of some income to smooth taxable income over time. Not only capital gains realizations, but to some extent the taxable income from business, can be subject to this kind of "self-averaging." Other transitory components of income, such as those due to unemployment or income windfalls, are essentially exogenous to the taxpayer.

The goal of this research program is to separate out the effect of transitory income on measured inequality, so as to get a better measure of the nature of, and trends in, a more permanent notion of inequality.

\section{B. Measuring Inequality Using Tax Return Data}

Most analysis of trends in U.S. inequality have relied on the data in the Current Population Surveys (CPS), conducted by the Census Bureau in March of most years. The analysis that follows is based on the data from the Internal Revenue Service (IRS) Statistics of Income Division's publicuse files of tax return information. This shift in data sources has its advantages and disadvantages, which I detail below.

An important advantage of the CPS is that it is designed to be a sample of the entire population and is therefore not restricted, for example, to tax filers. It also collects a wide variety of demographic information, including details about family structure and earnings disaggregated by family member. One disadvantage of the CPS is its poor coverage of capital income. Realized capital gains are not included at all, and other components of realized capital income are apparently severely underreported. In addition, all components of income, as well as total family income, are top-coded, so that there is no information on the upper tail 
of the distribution of income or its components. Clearly both of these problems are especially important in the analysis of the high-income population.

The strengths and weaknesses of the tax model data mirror those of the CPS. It covers only households that file tax returns, so it systematically excludes households whose low income makes them exempt from filing and who do not file a return in order to receive a refundable credit. It also excludes those who illegally fail to file a return. There is very little demographic information. On the plus side, the tax model data has very rich information on taxable sources of capital income, and is not top-coded.

\section{Trends in Snapshot Inequality}

Table 1 presents some summary information about the changes in the distribution of after-tax income, and its components, over the last two decades. The income concept used here, called expanded income, begins with adjusted gross income and then adds to it excluded long-term capital gains, excluded dividends and all adjustments. When an after-tax concept is used, tax liability net of credits is subtracted from expanded income. These changes are designed to make the income concept more comparable across years.

Expanded income is by no means an ideal measure of annual income. Among the problems are the failure to correct capital income for inflation, the exclusion of the rental value of owner-occupied homes and other consumer durables, the failure to subtract real interest payments, and the inclusion of capital gains on a realization, rather than an accrual, basis. Nevertheless, because many studies of tax return data use income concepts with these characteristics, it is important to understand the nature of inequality measures that are based on this type of information.

In Table 1 I make use of the Gini coefficient as a measure of inequality. ${ }^{1}$ The numbers in the first row document a striking increase in the inequality of after-tax expanded income between 1972 and 1988; the Gini coefficient rises from 0.445 to 0.544 over this period. For pre-tax income the increase is from .468 in 1972 to .496 in 1980 and .567 in 1988. This is broadly consistent with the Gramlich, Kasten, and Sammartino (1991) result that the Gini of pre-tax, pre-transfer income rose from 0.473 in

1 I am grateful to Shlomo Yitzhaki for providing the computer programs for calculating the Gini coefficient and decomposition discussed here. The figures of Table 1 are based on random subsamples of approximately 15,000 per year of the Individual Tax Model Files, a stratified random sample of about 100,000 tax returns made publicly available by the Statistics of Income Division of the Internal Revenue Service. 
TABLE 1.

Gini Coefficients and Decomposition of After-Tax Expanded Income and its Components and Pre-Tax Expanded Income, 1972-1988.

\begin{tabular}{|c|c|c|c|c|c|c|}
\hline & \multicolumn{3}{|c|}{1972} & \multicolumn{3}{|c|}{1976} \\
\hline & Gini & Share & Rho & Gini & Share & Rho \\
\hline $\begin{array}{l}\text { Expanded income } \\
\text { after tax }\end{array}$ & 0.445 & & & 0.458 & & \\
\hline Wages and salaries & 0.489 & 0.927 & 0.856 & 0.515 & 0.948 & 0.856 \\
\hline Capital gains & 1.052 & 0.055 & 0.760 & 1.066 & 0.042 & 0.733 \\
\hline Interest & 0.884 & 0.041 & 0.438 & 0.883 & 0.051 & 0.457 \\
\hline Dividends & 0.981 & 0.026 & 0.712 & 0.982 & 0.024 & 0.734 \\
\hline Schedule C & 1.188 & 0.053 & 0.562 & 1.286 & 0.047 & 0.542 \\
\hline Schedule E & 1.713 & 0.029 & 0.509 & 2.144 & 0.024 & 0.422 \\
\hline Schedule F & 2.465 & 0.006 & 0.320 & 6.664 & 0.003 & 0.326 \\
\hline Pension & 0.976 & 0.016 & 0.279 & 0.962 & 0.030 & 0.303 \\
\hline Other income & +2.716 & -0.007 & +0.006 & -1.937 & -0.014 & 0.029 \\
\hline $\operatorname{Tax}$ & +0.654 & -0.146 & +0.957 & +0.682 & -0.155 & +0.960 \\
\hline $\begin{array}{l}\text { Expanded income } \\
\text { before tax }\end{array}$ & 0.468 & & & 0.485 & & \\
\hline
\end{tabular}

1980 to 0.513 in 1985 and an estimated 0.523 in 1990. Table 1 also presents the Gini coefficient and shares of each of several components of after-tax income. ${ }^{2}$ It also lists, under the columns headed "rho," the Gini correlation between the component and after-tax income. ${ }^{3}$ As discussed in Lerman and Yitzhaki (1985), the Gini coefficient of income can be decomposed so that it is equal to the sum, over all components, of the product of the component's own Gini, its share in income, and the Gini correlation.

Because wages and salaries represent about 90 percent of after-tax income (and about 80 percent of pre-tax income), it is reasonable to look there for the origin of the change in inequality, and this strategy is rewarded. The second row of Table 1 reveals that between 1972 and 1988 the Gini coefficient of wages and salaries increased from 0.489 to 0.578 . Clearly a large part of the trend in overall inequality is associated with the increased inequality of wages and salaries.

2 The astute reader will notice the prevalence of Gini coefficients for income components that are in excess of one. This is due to the presence of negative values for these components, which means that the Lorenz curve lies partly below the $x$-axis.

3 The Gini correlation of component $k$ is the ratio of the covariance of $k$ with the observation's rank in the income distribution and the covariance of $k$ with the rank in the distribution of $k$. It ranges between -1 and +1 , taking on a value of +1 if the ranking by income and the ranking by $k$ are identical. 


\begin{tabular}{|c|c|c|c|c|c|c|c|c|}
\hline \multicolumn{3}{|c|}{1980} & \multicolumn{3}{|c|}{1984} & \multicolumn{3}{|c|}{1988} \\
\hline Gini & Share & Rho & Gini & Share & Rho & Gini & Share & Rho \\
\hline 0.467 & & & 0.502 & & & 0.544 & & \\
\hline 0.526 & 0.937 & 0.854 & 0.554 & 0.909 & 0.853 & 0.578 & 0.882 & 0.867 \\
\hline 1.088 & 0.053 & 0.781 & 1.061 & 0.070 & 0.780 & 1.086 & 0.062 & 0.781 \\
\hline 0.886 & 0.074 & 0.489 & 0.869 & 0.091 & 0.457 & 0.888 & 0.069 & 0.487 \\
\hline 0.975 & 0.030 & 0.773 & 0.963 & 0.026 & 0.686 & 0.967 & 0.029 & 0.666 \\
\hline 1.408 & 0.040 & 0.490 & 1.446 & 0.039 & 0.433 & 1.271 & 0.046 & 0.494 \\
\hline 4.581 & 0.053 & 0.270 & 653.00 & 0.000 & 0.210 & 3.582 & 0.020 & 0.497 \\
\hline-8.925 & -0.002 & 0.315 & -1.844 & -0.007 & 0.167 & -37.74 & 0.000 & 0.182 \\
\hline 0.955 & 0.034 & 0.255 & 0.945 & 0.041 & 0.348 & 0.932 & 0.067 & 0.490 \\
\hline 289.38 & 0.000 & 0.385 & -3.805 & -0.012 & 0.226 & -3.578 & -0.011 & 0.520 \\
\hline+0.682 & -0.179 & +0.957 & +0.687 & -0.159 & +0.956 & +0.731 & -0.164 & +0.962 \\
\hline 0.496 & & & 0.524 & & & 0.567 & & \\
\hline
\end{tabular}

Source: Random subsamples (of approximately 15,000 per year) of Individual Income Tax Model files. Note: Gini coefficients of sources of income with a share close to zero are unreliable indicators of the skewness of the distribution.

For all the years, subtracting tax liability reduces the dispersion of income as measured by the Gini, although the change is fairly small. In 1972 the reduction is 0.023 . It peaks in 1980 at 0.029 , when the ratio of tax liability to after-tax expanded income also reaches its peak of 0.179 . It declines in 1984 back to 0.022 and then turns slightly up in 1988 to 0.023 . Thus the federal income tax liability has done little, if anything, to offset the increasing dispersion of pre-tax incomes; in the 1980s it has slightly exacerbated the trend toward increased inequality of after-tax incomes, holding pre-tax incomes unchanged.

Comparing the Gini coefficient of pre-tax and post-tax incomes answers the question of what a total elimination of federal income taxes would do to inequality. Another meaningful question is how a marginal proportional change in taxes would affect overall income inequality. Lerman and Yitzhaki (1985) show that a 1 percent change in component $k$ changes the overall Gini by $s_{k}\left(p_{k} G_{k}-G\right) / 100$, where $s_{k}, p_{k}$ and $G_{k}$ are the share, Gini correlation, and own Gini of component $k$, respectively, and $G$ is the overall Gini. Performing this calculation reveals that a proportional 10 percent increase in taxes would have reduced the overall Gini in 1972 by 0.00264 , or 0.59 percent of its actual value. By 1988, the 
same experiment would have reduced the overall Gini by 0.00262 , or 0.48 percent of its actual value. ${ }^{4}$

\section{TIME-EXPOSURE INCOME}

\section{$D$. The Importance of Transitory Income}

The presence of transitory income, and the mobility of taxpayers across income classes, means that inequality of income in any given snapshot can exceed that of a more permanent notion of income, and that conclusions on the contribution of any source of income to inequality based on snapshots can be misleading. In this section I present some evidence on the importance of these issues for the period 1979 to 1986.

The source of this information is a panel of individual tax returns. Beginning in 1979, the IRS Statistics of Income Division has been collecting information from the tax returns of a randomly selected group of taxpayers. This panel, known as the Continuous Work History File, was developed for internal use, but the IRS has made this longitudinal data set available to academic researchers through a special arrangement with the Office of Tax Policy Research at the University of Michigan, in conjunction with the Ernst \& Young Tax Research Database. The panel now spans 1979 to 1986, with 1987 and 1988 expected soon. The panel is a nonstratified random sample chosen on the basis of the last four digits of the primary taxpayer's social security number (SSN). Of those numbers chosen, anyone filing a return is included in the sample. The first three years of the panel each contain in excess of 45,000 returns, though the last three years of the panel show a substantial drop in the number of observations (approximately 9,000 in 1982, 1984, and 1986, 19,000 in 1983 and 1985) due to budgetary limitations at the IRS. 5 Pooling all observations in the panel gives a sample size of 177,177 . Due largely to the small number of observations in 1982,1984, and 1986, the number of individu-

\footnotetext{
${ }^{4}$ Note that this procedure implies that a 100 percent reduction in taxes (i.e., complete elimination) would increase the Gini in 1988 by 0.0262 , whereas the actual difference between the pre-tax and after-tax Gini is only 0.023 . The discrepancy is due to the fact that the calculation in the text is precise only at the margin. Any nonincremental change in taxes would require a reranking of taxpayers by after-tax income, which would increase the Gini. For this reason the marginal calculation applied to the complete elimination of taxes overstates the actual difference between pre- and after-tax Gini coefficients.

5 The sample is drawn on the basis of the last four digits of the social security number of the primary (first listed on the tax return) taxpayer. In 1979 through 1981 the sample includes all returns filed in a calendar year with any of five four-digit endings. In 1982 only those returns with one of the five endings were drawn; in 1983 returns with two of the endings were chosen. The alternating one-ending, two-ending cycle was continued through 1986.
} 
als present in all eight years of the panel is limited to 5,780 taxpayers. The information contained in each observation is a subset of the information on the standard forms filed by the taxpayer, and varies slightly from year to year.

Attrition from the panel may occur for a number of reasons unrelated to deliberate change in the sample size, including death, a change in marital status, income below the minimum that would trigger filing, or simply the choice of which spouse (between two married, joint filers) is listed first on the tax form (and thus becomes the "primary" taxpayer whose SSN is the basis of selection). A taxpayer who files sufficiently late (in the calendar year after the return is due) will also escape inclusion.

It is not unreasonable to suspect that a panel of this sort may exhibit some drift relative to the population as a whole. Although each year's taxpayers in the panel may be representative of the population as a whole, the sampling method may cause a "survivorship" bias or "attrition" among those observations present in more than one year of the panel. Christian and Frischmann (1989) analyzed the first six years of the panel for attrition bias and concluded that the sample of taxpayers present in all those years shows statistically significant differences from population averages. Average income is about 20 percent higher and married couples (specifically, joint filers) are more numerous. Also, compared to a random sample, the fraction of returns for which the primary taxpayer claims an aged exemption (for being sixty-five or older) is lower in the initial year of the panel, rises more rapidly, and is higher in the final year of the panel.

Compared to the tax model files used in Section 3, the critical advantage of the panel data is its longitudinal nature, which allows the researcher the opportunity to identify transitory effects on income. Its principal disadvantage, other than the attrition bias, is the purely random nature of the sample, compared to the stratified random character of the tax model that heavily over-samples upper-income taxpayers.

Table 2 documents that there is a significant amount of mobility in and out of the upper-income classes from year to year, at least for this particular definition of income. In a typical year in the first half of the 1980s, more than 20 percent of taxpayers in the top decile of expanded income had not been in the top decile the previous year. For the top one percentile, the figure rises to 33 percent for 1982 through 1985. Mobility into (and out of) the top classes was extraordinary in 1986, presumably due to the large spurt in capital gains realizations that occurred in anticipation of tax increases due in 1987.

The presence of transitory income means that, in general, those with low income in a snapshot are probably not really as badly off as one 
TABLE 2.

Percentage of Those in Top Percentiles of Pre-Tax Expanded Income Who Were Not in That Group in the Previous Year, 1980-1986.

\begin{tabular}{rccccccc}
\hline & 1980 & 1981 & 1982 & 1983 & 1984 & 1985 & 1986 \\
\hline $10 \%$ & 22 & 24 & 21 & 22 & 20 & 23 & 27 \\
$5 \%$ & 26 & 28 & 26 & 26 & 24 & 27 & 31 \\
$1 \%$ & 28 & 30 & 33 & 33 & 33 & 33 & 40 \\
\hline
\end{tabular}

Source: 1979-1986 Panel of Individual Tax Returns, Balanced Panel Returns only.

year's income suggests and those with high income are probably not as well off as the snapshot suggests. In order to investigate the aggregate magnitude of these effects, I calculate for each taxpayer the average real income over the seven-year period from 1979 to 1985. Although available in the data set, 1986 is excluded from the calculations because of the extraordinary amount of capital gains realizations in that year. I refer to this concept as "time-exposure" income, to contrast it to "snapshot" income.

I purposely distinguish this concept from "permanent" or "lifetime" income. There is a separate literature (e.g., Fitzgerald and Maloney, 1990; Fullerton and Rogers, 1991), which attempts to calculate the inequality of permanent or lifetime income by purging from annual income not only the effect of transitory income but also the life-cycle and intercohort effect. The calculation procedure generally entails first estimating an equation that predicts annual income as a function of variables such as age, education, race, and, if longitudinal data is available, an individual-specific fixed effect, and then calculating the discounted value of projected annual incomes over the expected working life. Using data from 1969 to 1981 from the Panel Study on Income Dynamics, Fitzgerald and Maloney (1990) calculated that, not correcting for intercohort effects, the Gini coefficient for lifetime income was only 1.4 percent lower than that of 1979 income; when intercohort effects were eliminated, the Gini of lifetime income was 19.1 percent lower than that of 1979 income. They also found that the degree to which taxes and transfers reduce inequality is understated by a snapshot, suggesting that the fiscal system does more than smooth household income over the life cycle.

Table 3 illustrates the magnitude of the difference between snapshot and time-exposure income by arraying the latter by the former. There is clear evidence of reversion toward the mean. In 1983 snapshot income classes below $\$ 20,000$, time-exposure income is greater than 1983 in- 
TABLE 3.

Time Exposure Pre-Tax Expanded Income, 1979-1985, by 1983 Pre-Tax

Expanded Income Class.

\begin{tabular}{rcc}
$\begin{array}{c}1983 \text { Snapshot expanded } \\
\text { income class }\end{array}$ & $\begin{array}{c}\text { Average 1983 } \\
\text { expanded income }\end{array}$ & $\begin{array}{c}\text { Average time } \\
\text { exposure income, 1979-1985 }\end{array}$ \\
\hline$<0$ & -22923 & 34961 \\
$0-5000$ & 3063 & 7395 \\
$5-10,000$ & 7764 & 11168 \\
$10-15,000$ & 12586 & 14244 \\
$15-20,000$ & 17553 & 18967 \\
$20-25,000$ & 22372 & 22830 \\
$25-30,000$ & 27501 & 27477 \\
$30-50,000$ & 38596 & 38128 \\
$50-75,000$ & 59360 & 56640 \\
$75-100,000$ & 85229 & 80276 \\
$>100,000$ & 175707 & 153381 \\
\hline
\end{tabular}

Source: 1979-1986 Panel of Individual Tax Returns, Balanced Panel Returns only.

come. In 1983 classes above $\$ 50,000$, time-exposure income is clearly less than 1983 income. Between $\$ 20,000$ and $\$ 50,000,1983$ snapshot income on average is close to time-exposure income.

Perhaps the most striking aspect of Table 3 is the starkly different pictures one gets of the lowest income class. The average time-exposure income of those who, in 1983, had negative expanded AGI, was $\$ 34,961$. It has long been understood that those with negative income for tax purposes in a given year are often not truly poor, but this table shows just how important that phenomenon is. Not only are these people not poor, but on average they are solidly middle class.

\section{B. Income Inequality}

There have been several studies of the effect of extending the accounting period on measured inequality (e.g. Shorrocks, 1978a; and Benus and Morgan, 1975). The general conclusion, based on comparisons of annual measures of inequality to inequality measured over two or more years, has been that a longer accounting period reduces inequality very little. That conclusion must, though, be tempered by the tendency for relative inequality to increase as cohorts of individuals get older.

Table 4 compares the distribution of pre-tax expanded income and some of its components (ordered by income, not the component itself) when computed from snapshots and a time exposure; all columns sum to 100. For the columns headed SA, the figures shown are the simple average of the seven years' results when taxpayers are arranged by that 
TABLE 4.

Distribution of Snapshot Average Time-Exposure Pre-Tax Expanded Income, 1979-1985, and Some Components, by Expanded Income Percentiles.

\begin{tabular}{|c|c|c|c|c|c|c|c|c|}
\hline \multirow{2}{*}{$\begin{array}{l}\text { Expanded } \\
\text { income } \\
\text { percentile }\end{array}$} & \multicolumn{2}{|c|}{$\begin{array}{l}\text { Expanded } \\
\text { income }\end{array}$} & \multicolumn{2}{|c|}{$\begin{array}{c}\text { Wages \& } \\
\text { salaries }\end{array}$} & \multicolumn{2}{|c|}{$\begin{array}{l}\text { Interest \& } \\
\text { dividends }\end{array}$} & \multicolumn{2}{|c|}{$\begin{array}{c}\text { Business } \\
\text { (Sch. C) }\end{array}$} \\
\hline & SA & $\mathrm{TE}$ & SA & $\mathrm{TE}$ & $\mathrm{SA}$ & $\mathrm{TE}$ & SA & TE \\
\hline $0-10$ & 0.96 & 1.83 & 1.54 & 2.09 & 3.12 & 3.27 & 0.22 & 2.90 \\
\hline $10-20$ & 3.21 & 3.72 & 2.93 & 3.57 & 5.18 & 4.34 & 3.56 & 3.91 \\
\hline $20-30$ & 4.56 & 4.87 & 4.45 & 5.01 & 5.61 & 5.21 & 4.19 & 4.46 \\
\hline $30-40$ & 5.84 & 6.07 & 5.81 & 6.01 & 6.33 & 6.34 & 5.85 & 7.52 \\
\hline $40-50$ & 7.25 & 7.42 & 7.28 & 7.52 & 7.02 & 6.68 & 8.07 & 7.62 \\
\hline $50-60$ & 8.91 & 8.94 & 9.54 & 9.47 & 6.00 & 5.54 & 9.60 & 9.45 \\
\hline $60-70$ & 10.71 & 10.62 & 11.86 & 11.71 & 5.98 & 5.78 & 7.69 & 7.82 \\
\hline $70-80$ & 12.81 & 12.57 & 13.97 & 13.54 & 8.20 & 8.57 & 8.99 & 9.70 \\
\hline $80-90$ & 15.80 & 15.47 & 17.12 & 16.31 & 11.74 & 10.97 & 12.33 & 14.66 \\
\hline $90-95$ & 10.02 & 9.80 & 10.42 & 10.18 & 8.88 & 9.66 & 11.22 & 5.72 \\
\hline $95-99$ & 11.55 & 11.06 & 10.12 & 9.58 & 15.66 & 18.01 & 23.86 & 23.71 \\
\hline $99-100$ & 8.39 & 7.64 & 4.98 & 5.02 & 16.30 & 15.61 & 4.43 & 2.54 \\
\hline
\end{tabular}

Percentile Capital SA $\stackrel{\text { gains }}{\text { TE }}$ SA $\stackrel{\text { liability }}{\text { TE }}$

$\begin{array}{rrrrr}0-10 & 1.88 & 2.16 & 0.28 & 0.72 \\ 10-20 & 0.67 & 1.04 & 1.16 & 1.79 \\ 20-30 & 0.68 & 1.32 & 2.37 & 2.89 \\ 30-40 & 1.15 & 1.49 & 3.64 & 3.99 \\ 40-50 & 2.09 & 2.13 & 5.10 & 5.40 \\ 50-60 & 1.81 & 2.31 & 6.99 & 7.22 \\ 60-70 & 1.84 & 5.03 & 8.93 & 9.03 \\ 70-80 & 4.18 & 5.84 & 11.52 & 11.26 \\ 80-90 & 6.67 & 7.84 & 15.99 & 15.73 \\ 90-95 & 6.73 & 8.18 & 11.48 & 11.32 \\ 95-99 & 20.47 & 19.00 & 16.26 & 15.43 \\ 99-100 & 51.84 & 43.67 & 16.29 & 15.23\end{array}$

Source: 1979-1986 Panel of Individual Tax Returns, Balanced Panel Returns only.

year's expanded income. Thus, for example, the 0.96 in the first row of the first column means that, averaged over 1979 to $1985,0.96$ percent of total snapshot expanded income for that year is received by the lowest 10 percent of expanded income earners in that year. For the columns headed TE, the taxpayers are arranged by time-exposure income, so that 1.83 percent of time-exposure income is received by the lowest 10 percent of taxpayers when ranked by time-exposure income. 
Table 4 reveals that, although the distribution based on time-exposure income is less skewed than the average distribution based on snapshots, the difference is not striking. First consider the fraction of income earned by the top percentiles as an indicator of income distribution skewness. In the snapshot average, the top 1 percent, 5 percent, and 10 percent of income earners receive 8.39 percent, 19.94 percent, and 29.96 percent of income. For 1979-1985 time-exposure income, these classes receive 7.64 percent, 18.70 percent, and 28.50 percent of income, respectively. Another notable difference is the greater shares of income going to the lower income classes in time-exposure income ( 5.55 percent versus 4.17 percent for the bottom two deciles), reflecting the fact that a significant fraction of low incomes in a snapshot reflect transitory negative components.

One other fact worth noting now, and worth returning to in Section V, is the large difference in measured inequality for a snapshot of a random sample of taxpayers and a snapshot of only those taxpayers who appear in all years of the panel. For example, in 1984, the Gini of before-tax income for the former is 0.524 compared to 0.422 for those who appear in all years of the panel. The large decline is due to the fact that it is predominantly low-income taxpayers who do not appear in all years, and thus are dropped from the "balanced" panel of returns that includes only those who filed a timely return in each year from 1979 to 1986 . This results in a lower measure of inequality. Thus it is important to distinguish not only between a snapshot and a time-exposure picture of the income distribution, but also between snapshots of all returns filed in a year and a snapshot of all returns filed in a year by people who file in eight consecutive years.

\section{Time-Exposure vs. Snapshot Sources of Income}

It is also instructive to compare the snapshot and time-exposure distributions of sources of income. First focus on the top 1 percent of income earners in Table 4 . The average of the snapshot distribution from the balanced panel reveals that 51.84 percent of all capital gains are received by this group; by time-exposure income this figure falls to 43.67 percent. Thus a snapshot overstates the extent to which capital gains are received by high-income individuals. Nevertheless, by either measure this is largely a phenomenon of the upper-income classes. ${ }^{6}$

For interest and dividends, the story is quite different. Focusing on the top 5 percent of income earners, there is a greater concentration among

${ }^{6}$ This is consistent with other evidence that shows that most capital gains are realized by individuals who regularly have realizations. See Slemrod, Kalambokidis, and Shobe (1989). 
the highest-income classes using time-exposure compared to snapshot distributions- 33.62 percent versus 31.96 percent. The story here is that high interest and dividends really do characterize the permanently welloff taxpayers, and a snapshot obscures the picture by replacing some of these taxpayers with others who have temporarily high income. For the top 1 percent of income, the time-exposure concentration is slightly lower than the snapshot average concentration, but the difference is much less marked than for capital gains, 15.61 percent compared to 16.31 percent.

Table 5 shows, by percentile class, some sources of expanded income for an average of 1979 to 1985 snapshots and time-exposure income, respectively. Thus in this table the rows of SA figures and TE figures would each sum to 100 if all sources were included. Many of the same patterns of Table 4 appear here. The final columns, which portray tax liability as a fraction of pre-tax expanded income, are worth noting. Based on time-exposure income, the average tax burden continually increases with income and ranges from 6.07 percent for the lowest income class to 30.70 percent for the highest. In contrast, based on an average of snapshots, the lowest income classes have a lower average tax burden. The average tax liability of the highest class is also slightly lower in snapshots compared to time-exposure income, 29.99 percent as compared to 30.70 percent.

\section{LONG-TERM TRENDS FROM A TIME-EXPOSURE PERSPECTIVE}

Section III of this paper showed that snapshots of annual tax return data reveal a nearly continual increase in pre-tax income inequality between 1972 and 1988, with tax liability playing a small, or even negative, role in offsetting that trend. Section IV argued that snapshots of the 1980s overstate slightly the inequality of time-exposure income, a conceptually more appealing measure of well-being.

In this section I attempt to draw the two strands of this research together in order to answer the following type of question: Does comparing snapshots of 1972 and 1988 misstate the true change in inequality because of a change in the accuracy of a snapshot as a measure of timeexposure income? In particular I investigate the intriguing hypothesis that because of increased mobility, the increase in snapshot inequality overstates the increase in time-exposure inequality.

To address these issues I make use of an earlier panel of tax returns that spans the years 1967 to 1973 . As for the 1979 to 1986 panel, the 1967 to 1973 data set was created by drawing all tax returns whose primary 
TABLE 5.

Breakdown of Expanded Income, 1979-1985, into Sources of Income, by Percentile.

\begin{tabular}{|c|c|c|c|c|c|c|}
\hline \multirow{2}{*}{$\begin{array}{l}\text { Expanded } \\
\text { income } \\
\text { percentile }\end{array}$} & \multicolumn{2}{|c|}{ Wages \& salaries } & \multicolumn{2}{|c|}{$\begin{array}{l}\text { Interest \& } \\
\text { dividends }\end{array}$} & \multicolumn{2}{|c|}{$\begin{array}{l}\text { Business } \\
\text { (Sch. C) }\end{array}$} \\
\hline & $\mathrm{SA}$ & $\mathrm{TE}$ & SA & $\mathrm{TE}$ & SA & $\mathrm{TE}$ \\
\hline $0-10$ & 134.83 & 94.29 & 31.10 & 15.93 & 0.52 & 4.73 \\
\hline $10-20$ & 75.75 & 79.43 & 14.36 & 10.43 & 3.32 & 3.14 \\
\hline $20-30$ & 80.68 & 85.05 & 10.81 & 9.57 & 2.75 & 2.73 \\
\hline $30-40$ & 82.18 & 81.94 & 9.62 & 9.34 & 2.94 & 3.70 \\
\hline $40-50$ & 83.09 & 83.73 & 8.74 & 8.04 & 3.32 & 3.06 \\
\hline $50-60$ & 88.48 & 87.56 & 6.03 & 5.53 & 3.18 & 3.15 \\
\hline $60-70$ & 91.59 & 91.12 & 5.01 & 4.86 & 2.12 & 2.20 \\
\hline $70-80$ & 90.21 & 89.05 & 5.65 & 6.09 & 2.05 & 2.30 \\
\hline $80-90$ & 89.57 & 87.17 & 6.66 & 6.33 & 2.37 & 2.83 \\
\hline $90-95$ & 85.98 & 85.86 & 7.87 & 8.80 & 3.35 & 1.74 \\
\hline $95-99$ & 72.52 & 71.57 & 12.13 & 14.53 & 6.16 & 6.39 \\
\hline $99-100$ & 49.32 & 54.32 & 17.35 & 18.24 & 1.75 & 0.99 \\
\hline TOTAL & 82.69 & 82.67 & 8.91 & 8.93 & 2.98 & 2.98 \\
\hline \multirow[t]{2}{*}{ Percentile } & \multicolumn{2}{|c|}{$\begin{array}{c}\text { Capital } \\
\text { Gains }\end{array}$} & \multicolumn{2}{|c|}{$\begin{array}{c}\text { Tax } \\
\text { Liability }\end{array}$} & & \\
\hline & SA & $\mathrm{TE}$ & SA & $\mathrm{TE}$ & & \\
\hline $0-10$ & 8.81 & 4.68 & 4.61 & 6.07 & & \\
\hline $10-20$ & 0.71 & 1.11 & 5.50 & 7.41 & & \\
\hline $20-30$ & 0.55 & 1.08 & 7.97 & 9.15 & & \\
\hline $30-40$ & 0.70 & 0.97 & 9.59 & 10.14 & & \\
\hline $40-50$ & 1.07 & 1.14 & 10.83 & 11.21 & & \\
\hline $50-60$ & 0.79 & 1.03 & 12.07 & 12.44 & & \\
\hline $60-70$ & 0.61 & 1.88 & 12.84 & 13.09 & & \\
\hline $70-80$ & 1.21 & 1.84 & 13.86 & 13.79 & & \\
\hline $80-90$ & 1.58 & 2.01 & 15.59 & 15.66 & & \\
\hline $90-95$ & 2.56 & 3.30 & 17.64 & 17.78 & & \\
\hline 95-99 & 6.59 & 6.80 & 21.71 & 21.48 & & \\
\hline $99-100$ & 24.56 & 22.64 & 29.99 & 30.70 & & \\
\hline Total & 3.92 & 3.96 & 15.41 & 15.40 & & \\
\hline
\end{tabular}

Source: 1979-1986 Panel of Individual Tax Returns, Balanced Panel Returns only.

taxpayer had certain four-digit social security number endings. This procedure results in a random sample of taxpayers for any given year, but the sample of taxpayers for which there is a tax return in each of the seven years, the focus of our study, is not a random sample, and will exhibit the same sort of attrition biases discussed above. This attrition 
TABLE 6.

Percentage of Those in Top Percentiles of Expanded Income Who Were Not in that Group in the Previous Year, 1968-1973.

\begin{tabular}{rccccccc}
\hline & 1968 & & 1969 & 1970 & 1971 & 1972 & 1973 \\
\cline { 1 - 5 } \cline { 5 - 8 } & 20 & & 24 & 23 & 20 & 19 & 21 \\
$5 \%$ & 21 & & 24 & 24 & 23 & 22 & 23 \\
$1 \%$ & 20 & 20 & 24 & 25 & 24 & 23 \\
\hline
\end{tabular}

Source: 1979-1986 Panel of Individual Tax Returns, Balanced Panel Returns only.

bias is particularly troubling in this context, as taxpayers whose incomes are more subject to downward mobility are more likely to be excluded from the sample.

I look first directly at a simple indicator of income mobility. Table 6 reproduces Table 2 for the 1967 to 1973 period, showing the percentage of those in the top 1,5, and 10 percentiles that were not in that group in the previous year. There are clear differences between the two periods, especially for the top 1 percent and 5 percent groups. Over the 1968 to 1973 period, an average of 22.8 percent of those in the top 5 percent had not been in that group the year before; for the 1980 to 1986 period that figure rises to 26.9 percent ( 26.2 percent if 1986 is excluded). The difference is even larger for the top 1 percent of taxpayers. The average fraction who had not been among the top 1 percent in the previous year was 22.7 percent between 1968 and 1973; it increased to 32.9 percent between 1980 and 1986 (31.7 percent excluding 1986).

Thus there is some evidence that income mobility - at least among the highest income groups-increased between 1967 and 1973 and 1979 and 1986. It is, therefore, conceivable that some of the increase in snapshot inequality between these two periods does not correspond to an increase in inequality of a more permanent notion of income.

The first two columns of Table 7 address this issue by comparing the distribution of time-exposure income in the 1967 to 1973 panel to that of time-exposure income in the 1979 to 1985 period. In the later period the fraction of expanded income received by the poorest half of the population declined significantly, from 25.69 percent to 23.90 percent. The mirror image of this trend is an increase in the share of income earned by the top half, with one notable exception. The share of expanded income received by the top 1 percent declines from 10.42 percent to 7.64 percent between the two periods. Thus, based on these figures in Table 7, the characterization that "the poor got poorer and the rich got richer" must be amended to add "except for the very rich." The amendment regard- 
TABLE 7.

Comparison of Inequality Measures for Before-Tax Time-Exposure Income Using the 1967-1973 Panel and the 1979-1985 Panel.

\begin{tabular}{ccccc}
\hline Percentile & $1967-1973$ & $1979-1985$ & $1970-1973$ & $1982-1985$ \\
\hline $0-10$ & & & & \\
$10-20$ & 2.23 & 1.83 & 2.19 & 1.62 \\
$20-30$ & 3.96 & 3.72 & 4.06 & 3.61 \\
$30-40$ & 5.30 & 4.87 & 5.43 & 4.85 \\
$40-50$ & 6.53 & 6.06 & 6.60 & 6.01 \\
$50-60$ & 7.65 & 7.42 & 7.84 & 7.31 \\
$60-70$ & 8.77 & 8.94 & 9.00 & 8.90 \\
$70-80$ & 10.07 & 10.62 & 10.31 & 10.66 \\
$80-90$ & 11.62 & 12.57 & 11.93 & 12.69 \\
$90-95$ & 14.00 & 15.47 & 14.43 & 15.56 \\
$95-99$ & 8.89 & 9.80 & 9.14 & 9.94 \\
$99-100$ & 10.56 & 11.06 & 10.75 & 11.45 \\
& 10.42 & 7.64 & 8.26 & 7.40 \\
Before-Tax Gini & 100 & 100 & 100 & 100 \\
After-Tax Gini & .373 & .390 & .361 & .397 \\
\hline
\end{tabular}

Source: 1967-1973 and 1979-1986 Panel of Individual Tax Returns, Balanced Panel Returns only.

ing the very rich is reflected in the Gini summary measure of inequality, which between these two periods increased from 0.373 to only 0.390 , not nearly as large an increase as one might expect based on the snapshots of inequality discussed in Section III of this paper.

Compared to the results of Table 1 , the numbers in Table 7 might seem to suggest that much of the increase in inequality over the past two decades is an artifact of comparing snapshots of distributions, and that in particular the concentration of income in the highest income classes has been overstated. This conclusion is not warranted.

The principal reason for the discrepancy is that the first three years of the 1967 to 1973 period apparently predate the secular increase in inequality. In fact, the snapshot Gini coefficients from the balanced panel for 1967 and 1968 are higher than those of nearly any other year in either panel. ${ }^{7}$ Table 8 presents the Gini coefficients for each year of the two panels (excluding 1986 for the later panel, so that each panel contains

7 The measured Gini coefficient for 1968 is particularly high due to the presence in the sample of one return with a capital gain equal to more than 4 percent of the total income of all taxpayers in that year's sample. The actual snapshot inequality in 1969, and possibly 1968 , is due in part to the large amount of capital gains realizations in this year in anticipation of increased effective capital gains taxes, beginning in 1970. In this respect 1969 is like 1986. See Slemrod and Feldstein (1978). 
TABLE 8.

Gini Coefficients and Decomposition of Pre-Tax Time-Exposure Expanded Income, 1967-1973 and 1979-1985.

\begin{tabular}{|c|c|c|c|c|c|c|c|}
\hline & & $967-19$ & & & & 979-19 & \\
\hline & Gini & Share & Rho & & Gini & Share & Rho \\
\hline Time- & .373 & & & Time- & .390 & & \\
\hline Exposure & & & & Exposure & & & \\
\hline Income & & & & Income & & & \\
\hline 1967 & .431 & .126 & .896 & 1979 & .425 & .135 & .897 \\
\hline 1968 & .468 & . 148 & .940 & 1980 & .433 & .142 & .934 \\
\hline 1969 & .402 & . 141 & .942 & 1981 & .417 & .142 & .944 \\
\hline 1970 & .381 & .140 & .945 & 1982 & .410 & .139 & .950 \\
\hline 1971 & .383 & .142 & .937 & 1983 & .418 & .141 & .935 \\
\hline 1972 & .383 & .149 & .924 & 1984 & .422 & .148 & .922 \\
\hline 1973 & .381 & .153 & .882 & 1985 & .422 & .154 & .903 \\
\hline
\end{tabular}

Source: 1967-1973 and 1979-1986 Panel of Individual Tax Returns, Balanced Panel Returns only.

seven years), as well as a Gini decomposition of time-exposure income into its component years. The values of rho, which indicate the variability of income over time, are not clearly different across the two periods. A more formal comparison uses the measure of income mobility proposed by Shorrocks (1978b), the ratio of (what I call) time-exposure inequality to a weighted average of annual measures of inequality, where the weights are the share of annual income in aggregate timeexposure income. This comes to 0.9229 for 1967 to 1973 and 0.9260 for 1979 to 1985, indicating a slight decline in income mobility.

The final two columns of Table 6 confirm the importance of 1967 to 1969 for the conclusion that inequality did not increase much between the two panel periods. These columns recalculate the distribution of before-tax time-exposure expanded income, where time-exposure income is calculated using only 1970 to 1973 for the earlier panel and only 1982 to 1985 for the later panel. The comparison of four-year timeexposure incomes shows that there is a much less noticeable difference in the concentration of incomes at the top. The increase in the Gini coefficient of both pre-tax and after-tax income is about twice as large as is evident when comparing the seven-year panels. The fact that the increase in inequality between the two periods is less than one would have guessed from Table 1 is primarily due to the difference in the samples studied; Table 1 refers to the entire taxpaying population, while Tables 6 and 7 refer only to those taxpayers who filed returns in each of several years.

Thus it appears that there was no significant change between 1967 and 
1973 and 1979 and 1985 in the degree to which snapshots overestimate the inequality in time-exposure income. The small increase in the Gini coefficient of time-exposure income predominantly reflects the fact that the earlier period includes the high inequality years of 1967 through 1969.

\section{CONCLUSIONS AND CAVEATS}

The principal conclusions from this study can be summarized as follows:

1. Based on annual tax return data, the inequality of pre-tax income has been increasing steadily between 1972 and 1988. The major factor in this trend has been the increasing inequality in the distribution of wages and salaries.

2. Assuming exogenous pre-tax incomes, income taxation slightly decreases inequality. Overall it has neither stemmed nor contributed significantly to the general trend. Since 1980 the contribution of the income tax to decreasing inequality has declined slightly.

3. Replacing annual income with "time-exposure" income, defined as average real income over the whole period, does not significantly reduce the measured degree of inequality in the 1979 to 1985 period, although the fraction of income received by the lowest decile does increase substantially. This procedure does, though, reduce the contribution to inequality of certain sources of income such as capital gains and increase the contribution of other sources such as interest and dividends.

4. There is only a slight increase between the 1967 to 1973 and 1979 to 1985 periods in the inequality of time-exposure income, a finding apparently at odds with the measures of snapshot inequality. Much of the discrepancy is, however, due to the inclusion in the former period of the relatively high inequality years between 1967 and 1969. There is no systematic evidence that the comparison of snapshots between the two periods overstates the growth of inequality of a more permanent notion of income.

Because all of these conclusions are based on an examination of tax return data, several important caveats apply. The most important is that, because households with income below a filing threshold need not file a return, the distribution of taxpayers in any snapshot will omit a significant fraction of the lower tail of the distribution of household income. Moreover, because the real filing threshold is not constant over time, the extent of taxpayers omitted from the snapshot changes. Thus, conclu- 
sions 1 and 2 pertain to the universe of taxpayers, and not necessarily to the universe of all households.

An additional caveat applies to conclusions 3 and 4, which are based on distributions of snapshots and time exposures. These comparisons are based on a subset of taxpayers-those who filed returns in each of a number of consecutive years. Because this sampling criterion will tend to exclude taxpayers whose income occasionally falls below the filing threshold, it will likely understate the amount of snapshot income mobility. Furthermore, because the real filing thresholds change, the extent of this effect may be different across the two panels studied here.

These caveats are meant to be taken seriously. They suggest that further research should focus on the extent to which the trends in the distributions of income and income sources among taxpayers reflect accurately the trends in the distribution for all households, and on the degree to which income mobility is misstated by ignoring taxpayers who do not regularly file returns.

Policy decisions affecting the distribution of income cannot, alas, await these desirable refinements to the techniques employed here. Much analysis of alternative tax policies focuses solely on the taxpaying population, without placing the results into the larger context of all households. Thus it is valuable to know which kinds of conclusions about taxation and inequality based on snapshots are likely to apply to a more permanent notion of income. This paper is a first step in that direction.

\section{REFERENCES}

Beach, Charles (1989). "Dollars and Dreams: A Reduced Middle Class-Alternative Explanations," The Journal of Human Resources 24(1).

Benus, J., and J. N. Morgan (1975). "Time Period, Unit of Analysis and Income Concept in the Analysis of Income Distribution." In The Personal Distributions of Income and Wealth. J. D. Smith, ed. New York: National Bureau of Economic Research.

Christian, Charles W., and Peter J. Frischmann (1989). "Attrition in the Statistics of Income Panel of Individual Returns," National Tax Journal, 62(4), December. 495-501.

Danziger, Sheldon, Peter Gottschalk, and Eugene Smolensky (1989). "How the Rich Have Fared, 1973-1987," American Economic Review 79, 310-314.

Duncan, Greg J., Timothy M. Smeeding, and Willard Rodgers (1991). "W(h)ither the Middle Class? A Dynamic View." Prepared for the Levy Institute Conference on Income Inequality, Bard College, June 18-20.

Fitzgerald, John and Tim Maloney (1990). "The Impact of Federal Income Taxes and Cash Transfers on the Distribution of Lifetime Household Income, 196981." Public Finance Quarterly 18 (2), April, 182-197. 
Fullerton, Don, and Diane Lim Rogers (1991). Who Bears the Lifetime Tax Burden? Manuscript prepared for the Brookings Institution.

Gramlich, Edward, Richard Kasten, and Frank Sammartino (1991). "Growing Inequality in the 1980's: The Role of Taxes and Transfers." In Increasing Income Inequality: What Matters and What Doesn't. S. Danziger and P. Gottschalk, eds. New York: Russell Sage Foundation.

Karoly, L. A. (1991). "The Trend in Inequality Among Families, Individuals, and Workers in the United States: A Twenty-Five Year Perspective." In Increasing Income Inequality: What Matters and What Doesn't. S. Danziger and P. Gottschalk, eds. New York: Russell Sage Foundation.

Lerman, Robert I., and Shlomo Yitzhaki (1985). "Income Inequality Effects by Income Source: A New Approach and Applications to the United States." Review of Economics and Statistics 47, February, 151-155.

Levy, Frank (1987). Dollars and Dreams: The Changing American Income Distribution. New York: Russell Sage.

Levy, Frank, and Richard J. Murname (1991). "Earnings Levels and Earnings Inequality: A Review of Recent Trends and Proposed Explanations." University of Maryland, Unpublished manuscript, February.

Lindsey, Lawrence (1990). The Growth Experiment. New York: Basic Books.

Poterba, James M. (1989). "Lifetime Incidence and the Distributional Burden of Excise Taxes." American Economic Review 79 (2) May, 325-330.

Shorrocks, Anthony F. (1978a). "Income Inequality and Income Mobility." Journal of Economic Theory 19, 376-393.

(1978b). "Income Stability in the United States," London School of Economics, Unpublished manuscript, December.

Slemrod, Joel (1983). "Do We Know How Progressive the Income Tax System Should Be?" National Tax Journal September. 36, 361-369.

Slemrod, Joel, and Martin Feldstein (1978). "The Lock-In Effect of the Capital Gains Tax: Some Time-Series Evidence." Tax Notes August. 134-135.

Slemrod, Joel, Laura Kalambokidis, and William Shobe (1989). "Who Realizes Capital Gains?" Tax Notes October 23. 494-495.

Varian, Hal (1980). "Redistributive Taxation as Social Insurance." Journal of Public Economics 14, 49-68. 
